\title{
Impact of bronchiectasis on long-term survival in patients with acute exacerbation of chronic obstructive pulmonary disease
}

\section{Ying Zhang}

Department of Respiratory and Critical Care Medicine区Beijing Institute of Respiratory Medicine and Beijing Chao-Yang Hospital, Capital Medical University

\section{Shu Zhang}

Department of Respiratory and Critical Care Medicine, Beijing Chao-Yang Hospital,Capital Medicine University

\section{Yan-Li Gao}

Department of Radiology,Beijing Chao-Yang Hospital,Capital Medical University

\section{Zhen Wang}

Department of Respiratory and Critical Care Medicine, Beijing Chao-Yang Hospital,Capital Medical University

\section{Xiao-Ning Bu}

Department of Respiratory and Critical Care Medicine, Beijing Chao-Yang Hospital, Capital Medicine University

\section{Ke-Wu Huang}

Department of Respiratory and Critical Care Medicine, Beijing Chao-Yang Hospital,Capital Medical University

\section{Huan-Zhong Shi ( $\nabla$ shihuanzhong@sina.com )}

Beijing Chao-Yang Hospital, Capital Medical University

\section{Ying-Xiang Lin}

Department of Respiratory and Critical Care Medicine, Beijing Chao-Yang Hospital,Capital Medical University

\section{Research article}

Keywords: Chronic Obstructive Pulmonary Disease; bronchiectasis; mortality; prognostic influence

Posted Date: June 12th, 2019

DOl: https://doi.org/10.21203/rs.2.10220/v1 
License: (c) (i) This work is licensed under a Creative Commons Attribution 4.0 International License. Read Full License 


\section{Abstract}

Background Only few studies have reported the association between bronchiectasis and mortality in patients with Chronic Obstructive Pulmonary Disease (COPD) and the results were controversial. This study aimed at assessing the prognostic influence of bronchiectasis on COPD patients and comparing differences of prognostic influence of different types of bronchiectasis on COPD patients. Patients and methods This study enrolled patients hospitalized for COPD exacerbation between 2013 and 2014 . Bronchiectasis was identified on high-resolution computed tomography (HRCT) within 2 years prior to this hospitalization due to COPD exacerbation and Smith score was used to determine the extent of bronchiectasis. Clinical data were obtained from electronic inpatient medical record. The survival data were obtained through telephone follow-up or electronic medical record. Cox regression analysis was used to assess the prognostic influence of bronchiectasis on COPD patients. Results 748 COPD patients were included in this study. 318 patients were identified to have bronchiectasis. During a median followup time of 46 months, 624 COPD patients completed follow-up. There were 210 deaths, 112 of whom were comorbid bronchiectasis patients. Comorbid bronchiectasis patients revealed higher mortality than without bronchiectasis patients in 3 years and the whole follow-up, other than in hospital, 1 year and 2 years. The presence of bronchiectasis and its severity were independently associated with increased mortality of COPD patients. The presence of cystic/varicose bronchiectasis revealed higher mortality than cylindrical bronchiectasis and was independently associated with increased mortality of comorbid bronchiectasis patients. Conclusions The presence of bronchiectasis and its severity were independently associated with increased risk of all-cause mortality and mainly affected the long-term mortality of COPD patients. The presence of cystic/varicose bronchiectasis predicted higher death risk of COPD patients.

\section{Introduction}

COPD (Chronic Obstructive Pulmonary Disease) is a heterogeneous disease with high morbidity and mortality and its mortality will continue to increase in the coming decades. Therefore, identification of COPD patients at risk for higher mortality is very important. Currently, many variables which are associated with increased mortality of COPD such as severe exacerbations of COPD [1], pulmonary hypertension and weight loss, age, gender [2], some biologic parameters, such as C-reactive protein, neutrophil count, eosinophil count [3], fibrinogen and hypercapnia [4-5], Pseudomonas aeruginosa isolates have been detected [6]. However, these evidences are insufficient to explain the whole picture of COPD death risk. COPD often coexists with other diseases (comorbidities) which may have significant impacts on prognosis of COPD patients. With increasing use of high-resolution computed tomography (HRCT) in assessment of COPD, a high prevalence of previously undiagnosed bronchiectasis was found in COPD patients, ranging from 8.1-69\% [7-19]. Some previous studies suggested the presence of bronchiectasis predicted worse outcome of COPD patients [9-11, 13, 15, 20].Therefore, bronchiectasis was proposed as one of COPD comorbidities by 2014 global initiative for chronic obstructive lung disease (GOLD). Up to now, there have been limited studies related to prognostic impact of bronchiectasis on COPD patients and the results were controversial $[7,11,13,21]$. 
Bronchiectasis is described as cylindrical, varicose and cystic types according to morphology [22]. The previous studies reported most of radiological bronchiectasis were cylindrical in COPD population, and a few of bronchiectasis were varicose/cystic $[8,13]$. Mao et al found comorbid cylindrical bronchiectasis patients presented higher oxygen partial pressure and moderate dyspnea than comorbid cystic bronchiectasis patients [13]. Another study revealed that there were more frequent mucopurulent sputum and more severe airway obstruction in comorbid cystic/varicose bronchiectasis patients compared with comorbid cylindrical bronchiectasis patients [8]. Therefore, we suspected that whether the presence of cystic/varicose bronchiectasis predicted worse prognosis of COPD patients. Up to now, there has been no study about the relationship between types of bronchiectasis and mortality of COPD patients. In the present study, our main aims were to assess the prognostic influence of the presence of bronchiectasis diagnosed on HRCT within 2 years prior to this hospitalization due to COPD exacerbation and its severity on COPD patients. In addition, we also compared differences of prognostic influence of different types of bronchiectasis on COPD patients.

\section{Materials And Methods}

\section{Study subjects}

1148 patients firstly hospitalized for COPD exacerbation at Beijing Chao-Yang Hospital of affiliated hospital of Capital Medical University between January 1, 2013 and December 31, 2014 were identified. COPD was defined by smoking history $\geq 10$ pack-year or/and biomass history $\geq 10$ years and

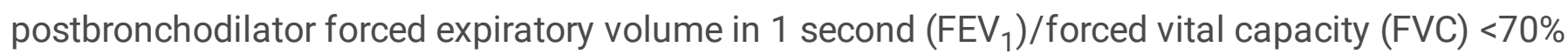
according to GOLD [23]. Patients who underwent HRCT scans within 2 years prior to first hospitalization due to COPD exacerbation between January 1, 2013 and December 31, 2014 were included in this study. We excluded 400 patients admitted with COPD exacerbation. Excluded patients included: 174 patients with doctor diagnosed bronchiectasis or asthma before COPD; 4 patients with interstitial lung disease; 14 patients with active cancer; 22 patients with history of lobectomy; 1 patient with active tuberculosis; 7 patients with severe lung damage resulting from previous pulmonary tuberculosis ("destroyed lung"); 10 patients with allergic bronchopulmonary aspergillosis ("ABPA"); 125 patients without available HRCT scans; 19 patients with unexplainable HRCT; 24 patients admitted to hospital because of comorbidities rather than COPD exacerbation. Of 1148 COPD patients were initially eligible for the study, 748 COPD patients were included in this study after exclusion. The earliest hospitalization data for patients repeatedly hospitalized for COPD exacerbation between January 2013 and December 2014 were used for analysis.

\section{Lung HRCT analysis}

Chest HRCT was performed using a 64-MDCT system (LightSpeed VCT, GE Healthcare). The presence and the extent of radiological bronchiectasis were independently evaluated and interpreted by a 
radiologist and a respiratory physician who were blind to clinical data of study subjects. If there were differences in the readings, the radiologist and the respiratory physician discussed the case and reached a final consensus. The diagnostic criteria of bronchiectasis were as follows [24]: (1) lack of tapering of bronchia; (2) the internal diameter of the dilated bronchus was greater than that of the adjacent pulmonary artery; (3) the peripheral bronchus can be seen within the $1 \mathrm{~cm}$ of the costal pleural surface or adjacent mediastinal pleural surface. The extent of bronchiectasis was scored according to the scoring system suggested by Smith $(0=0 \%, 1<25 \%, 2=25-49 \%, 3=50 \%-74 \%, 4 \geq 75 \%)$. The lingula was counted as a separate lobe, therefore, each patient may have a maximum score of 24 [22].If bronchiectasis was identified only in one pulmonary segment, it was not counted, as this may exist in a significant percentage of healthy population $[25,26]$.Therefore, COPD patients with a total score of 2 or more were considered as comorbid clinically significant bronchiectasis patients, while those with a score of 0 or 1 were counted as normal. The types of bronchiectasis were defined according to the morphology of bronchiectasis [22].

\section{Clinical variables}

Data that were collected from electronic inpatient medical record included age, sex, body mass index; smoking status; clinical outline (Time since onset of symptoms, daily expectoration, history of dyspnea, length of hospital); hospitalization for acute exacerbation of COPD in the previous year; previous history and comorbidities; laboratory blood tests; sputum pathogenic microorganism tests; post-bronchodilator pulmonary function within 1 year prior to this COPD exacerbation.

\section{Follow-up Assessment}

The follow-up was completed on March 1, 2018. The endpoint event of this study was all-cause mortality of each patient. Information about death events of COPD patients was obtained by telephone contact with these patients or their relatives or from electronic inpatient medical record. A patient was considered loss of follow-up if we were unable to contact with the patient during the study period. For each patient, the end date of follow-up was the date of death or the last contact of the patient.

\section{Data analysis}

Quantitative variables were expressed as mean \pm standard deviation (SD) and qualitative variables were expressed as absolute numbers and percentages. In the bivariate analysis, Student's t test was used for comparison of normally distributed data and Mann-Whitney $U$ test was used for comparison of nonnormally distributed data between two groups. The chi-square test was used for comparison of qualitative variables between two groups. Cox's proportional hazard regression model was used for analysis of independent risk factors of mortality of COPD patients. The following initial factors were examined for 
the prognostic value of COPD patients: sex, age, smoking history, length of hospitalization, time since onset of symptoms, daily expectoration, hemoglobin, albumin, fibrinogen, presence of PPMs (potential pathogenic microorganisms) in sputum, previous tuberculosis history, pulmonary heart disease, ischemic heart disease, arrhythmias, heart failure, Pseudomonas aeruginosa isolates, hospitalization for acute exacerbation of COPD in the previous year, the presence of bronchiectasis, the Smith score of bronchiectasis or bronchiectasis type. Results were expressed as hazard ratio (HR) and 95\% confidence interval (Cl). Hazard ratios (HRs) were presented in two ways: (1) for comorbid bronchiectasis subjects compared with the absent of bronchiectasis subjects; (2) the quantitative variables "Smith score" instead of the dichotomous variables "presence of bronchiectasis" compared with the absent of bronchiectasis subjects. In addition, Cox's proportional hazard regression model was also used for the analysis of prognostic influence of different types of bronchiectasis on COPD patients. The forward stepwise method was used and variables with a $p$ value $>0.1$ were removed from the model. Finally, Kaplan-Meier survival analysis were performed with the log-rank test to compare survival curves between patients with and without bronchiectasis or among absent, cylindrical, varicose/cystic bronchiectasis patients. A $p$ value of $<0.05$ was considered to be statistically significant. Analyses were performed with SPSS version 23(SPSS Chicago IL).

\section{Discussion}

Our study subjects were based on inpatients with COPD exacerbation, which was different from the previous studies from stable COPD patients. Our findings predicted that the presence of bronchiectasis and its severity were independently associated with all-cause mortality in patients with COPD exacerbation. Meanwhile, further analysis revealed the presence of cystic/varicose bronchiectasis predicted worse prognosis of COPD patients than that of cylindrical bronchiectasis, which was the first study showing the relationship between different types of bronchiectasis and mortality of COPD patients.

A high proportion of radiological bronchiectasis in COPD patients in our study was $42.5 \%$. Although there were no studies which had definitely reported the causal relationship between COPD and bronchiectasis, the point was suspected by the condition: the previous study reportedup to $40 \%$ COPD patients had high risk of a large number of meaningful bacterial colonization, especially in patients with a higher degree of airway obstruction [27]. This situation impairs host defense mechanisms [28], subsequently increases airway inflammation reaction and progressive lung structural damage, which is a vicious cycle and provides a base for formation of bronchiectasis. In our study, identification of bronchiectasis in COPD patients was associated with some worse functional and physiological parameters in COPD patients, which were in agreement with previous studies $[10,11,13,15]$.These findings predicted comorbid bronchiectasis patients might have worse prognosis.

During the long-term follow-up period, COPD patients with bronchiectasis showed a higher mortality than those without bronchiectasis. However, there was no significant difference in mortality within 2 years. This point may be suspected by this condition: increasing exacerbation frequency is associated with higher mortality and exacerbations in the previous year is the single best predictor of future exacerbations 
[29-30].The previous study reported the presence of bronchiectasis was associated with frequent exacerbation or hospitalization [12], which may predict comorbid bronchiectasis patients have frequent future exacerbations and subsequently increased bronchiectasis extent, furtherly resulted in an increased risk in long-term mortality of COPD. Otherwise, it may also be associated with a relatively low in mortality of COPD within 2 years. This is only a guess and needs to be confirmed by further research. Meanwhile, our data showed the presence of bronchiectasis was independently associated with all-cause mortality of COPD adjusted for other variables, which was consistent with the studies of Martinez Garcia et aland Mao et aland contrary to another two studies from Gatheral and Jairam et al $[11,13,7,21]$.The discordance could be explained by difference in study design. The first two studies were mainly concerned with the presence of bronchiectasis considered as a dichotomous variable, while the latter two studies were concerned with severity of bronchiectasis. When using quantitative variable "Smith score" of bronchiectasis instead of the dichotomous variable "presence of bronchiectasis", this result was also confirmed. In view of our study subjects who were patients of severe exacerbation of COPD, early death may be associated with this acute exacerbation of COPD. Therefore, further analysis was performed after excluding patients who died in hospital and within 90 days after discharge, which revealed bronchiectasis was still independently associated with increased all-cause mortality of COPD patients, furtherly confirmed radiological bronchiectasis in COPD patients could be used as a new and distinct clinical phenotype [31],mainly affected the long-term survival of COPD patients.

In our study, comorbid radiological bronchiectasis in COPD patients was mainly cylindrical type. In the previous study, the presence of cystic/varicose bronchiectasis in COPD patients presented more clinical symptoms, more severe lung function than cylindrical bronchiectasis ${ }^{8}$ and was associated with bacterial colonization [32]. In our study, comorbid cystic/varicose bronchiectasis patients presented higher Pseudomonas aeruginosa isolates compared with cylindrical bronchiectasis patients. Because Pseudomonas aeruginosa isolates [6,33], severe lung function may be associated with increased mortality in COPD patients [34],we suspected whether cystic/varicose bronchiectasis predicted worse prognosis in COPD patients. Our data revealed COPD patients without bronchiectasis presented the best prognosis, while comorbid cystic/varicose bronchiectasis patients presented the worst prognosis, the prognosis of comorbid cylindrical bronchiectasis patients lay between two groups. Furthermore, we perceived the presence of cystic/varicose bronchiectasis was independently associated with an increased risk of death of COPD patients with bronchiectasis. In order to minimize the possibility that the presence of bronchiectasis was mainly from primary bronchiectasis with airflow obstruction rather than secondary to COPD, our further analysis was performed and the data result revealed that the presence of cylindrical bronchiectasis was still a prognostic risk factor for mortality of COPD after excluding comorbid cystic/varicose bronchiectasis patients. These studies furtherly confirmed comorbid bronchiectasis especially cystic/varicose bronchiectasis predicted worse prognosis of COPD patients.

This study has several limitations. Firstly, due to nature of the retrospective study, some variables which may affect prognosis of COPD patients such as lung function and body mass index have more missing data, therefore, they were not included in survival analysis. Secondly, it was still difficult to distinguish 
whether bronchiectasis was associated with COPD especially comorbid severe bronchiectasis after excluding some known causes of secondary bronchiectasis. Finally, some data with regard to management of COPD patients in follow-up period such as lung rehabilitation and medicine usage such as antibiotics and vaccination were not included in survival analysis. These factors may influence our results analysis.

In summary, based on the current study, the presence and the severity of bronchiectasis were independently associated with prognosis of COPD patients. In addition, another significant discovery was that the presence of varicose/cystic bronchiectasis predicted worse prognosis of COPD than that of cylindrical bronchiectasis. Furtherly rigorous and large-scale prospective studies are needed to affirmed causal relationship between bronchiectasis and COPD and the prognostic influence of bronchiectasis on COPD patients.

\section{List Of Abbreviations}

COPD, Chronic Obstructive Pulmonary Disease; HRCT, high-resolution computed tomography; HR, hazard ratio; $\mathrm{Cl}$, confidence interval; PPMs, potential pathogenic microorganisms.

\section{Declarations}

\section{Acknowledgements}

Not applicable.

\section{Funding}

This work was supported by National Key R\&D Program of China (2016YFC1303900); the Beijing Municipal Administration of Hospitals' Mission Plan, China (No. SML20150301); Capital's Funds for Health Improvement and Research (No. CFH2016-4-1062) and Chinese Medical Association Chronic Respiratory Disease Fund (No. CRD 08020440122).

\section{Availability of data and materials}

The datasets used and analyzed during the current study are available from the corresponding author on reasonable request.

\section{Authors' contributions}


Y.Z participated in the design of the study, performed the experiments, data analysis, and drafted manuscript. Y.L.G evaluated and interpreted radiological bronchiectasis. H.Z.S, Y.X.L designed the study and supervised the experimental work, analyzed the result and revised the manuscript. S.Z, Z.W, X.N.B, K.W.H participated in reviewing and revised the manuscript. All authors reviewed the manuscript.

\section{Ethics approval and consent to participate}

The research scheme was approved by the ethics committee of Beijing Chao-Yang Hospital (IRB No.201723). Informed consent from patients was not required by the committee because this study was the noninterventional, observational design of the protocol and posed no risk or harm to the subjects included in the study.

\section{Consent for publication}

Not applicable.

\section{Competing interests}

The authors declare that they have no competing interests.

\section{References}

1. Soler-Cataluña JJ, Martínez-García MA, Román Sánchez P, Salcedo E, Navarro M, Ochando R.Severe acute exacerbations and mortality in patients with chronic obstructive pulmonary disease. Thorax. 2005;60(11):925-931. doi:10.1136/thx.2005.040527.

2. McGhan R, Radcliff T, Fish R, Sutherland ER, Welsh C, Make B. Predictors of rehospitalization and death after a severe exacerbation of COPD. Chest. 2007;132(6):1748-1755. doi:10.1378/chest.06-3018.

3. Mendy A, Forno E, Niyonsenga T, Gasana J. Blood Biomarkers as Predictors of Long-Term Mortality in COPD. Clin Respir J. 2018;12(5):1891-1899. doi:10.1111/crj.12752.

4. Duvoix A, Dickens J, Haq I, Mannino D, Miller B, Tal-Singer R, et al. Blood fibrinogen as a biomarker of chronic obstructive pulmonary disease. Thorax. 2013;68(7):670-676. doi:10.1136/thoraxjnl-2012-201871.

5. Hartl S, Lopez-Campos JL, Pozo-Rodriguez F, Castro-Acosta A, Studnicka M, Kaiser B, et al. Risk of death and readmission of hospital-admitted COPD exacerbations: European COPD Audit. Eur Respir J. 2016;47(1):113-121. doi:10.1183/13993003.01391-2014. 
6. Almagro P, Salvadó M, Garcia-Vidal C, Rodríguez-Carballeira M, Cuchi E, Torres J, et al. Pseudomonas aeruginosa and mortality after hospital admission for chronic obstructive pulmonary disease.

Respiration. 2012;84(1):36-43. doi:10.1159/000331224.

7. Gatheral T, Kumar N, Sansom B, Lai D, Nair A, Vlahos I, et al. COPD-related bronchiectasis; independent impact on disease course and outcomes. COPD. 2014;11(6):605-614.

doi:10.3109/15412555.2014.922174.

8. O'Brien C, Guest PJ, Hill SL, Stockley RA. Physiological and radiological characterisation of patients diagnosed with chronic obstructive pulmonary disease in primary care. Thorax. 2000;55(8):635-642.

9. Patel IS, Vlahos I, Wilkinson TM, Lloyd-Owen SJ, Donaldson GC, Wilks M, et al. Bronchiectasis, exacerbation indices, and inflammation in chronic obstructive pulmonary disease. Am J Respir Crit Care Med. 2004;170(4):400-407. doi:10.1164/rccm.200305-6480C.

10. Martínez-García MÁ, Soler-Cataluña JJ, Donat Sanz Y, Catalán Serra P, Agramunt Lerma M, Ballestín Vicente J, et al. Factors associated with bronchiectasis in patients with COPD. Chest. 2011;140(5):11301137. doi:10.1378/chest.10-1758.

11. Martínez-García MA, de la Rosa Carrillo D, Soler-Cataluña JJ, Donat-Sanz Y, Serra PC, Lerma MA, et al. Prognostic value of bronchiectasis in patients with moderate-to-severe chronic obstructive pulmonary disease. Am J Respir Crit Care Med. 2013;187(8):823-831. doi:10.1164/rccm.201208-15180C.

12. Kawamatawong T, Onnipa J, Suwatanapongched T. Relationship between the presence of bronchiectasis and acute exacerbation in Thai COPD patients. Int J Chron Obstruct Pulmon Dis. 2018; 13:761-769. doi:10.2147/COPD.S139776.

13. Mao B, Lu HW, Li MH, Fan LC, Yang JW, Miao XY, et al. The existence of bronchiectasis predicts worse prognosis in patients with COPD. Sci Rep. 2015; 5:10691. doi:10.1038/srep10961.

14. Bafadhel M, Umar I, Gupta S, Raj JV, Vara DD, Entwisle JJ, et al. The role of CT scanning in multidimensional phenotyping of COPD. Chest. 2011;140(3):634-642. doi:10.1378/chest.10-3007.

15. Jin J, Yu W, Li S, Lu L, Liu X, Sun Y. Factors associated with bronchiectasis in patients with moderatesevere chronic obstructive pulmonary disease. Medicine (Baltimore). 2016;95(29): e4219. doi:10.1097/MD.0000000000004219.

16. Dou S, Zheng C, Cui L, Xie M, Wang W, Tian H, et al. High prevalence of bronchiectasis in emphysemapredominant COPD patients. Int J Chron Obstruct Pulmon Dis. 2018; 13:2041-2047. doi:10.2147/COPD.S163243.

17. Dou S, Zheng C, Ji X, Wang W, Xie M, Cui L, et al. Co-existence of COPD and bronchiectasis: a risk factor for a high ratio of main pulmonary artery to aorta diameter (PA: A) from computed tomography in COPD patients. Int J Chron Obstruct Pulmon Dis. 2018; 13:675-681. doi:10.2147/COPD.S156126. 
18. Bak SH, Kim S, Hong Y, Heo J, Lim MN, Kim WJ.Quantitative computed tomography features and clinical manifestations associated with the extent of bronchiectasis in patients with moderate-to-severe COPD. Int J Chron Obstruct Pulmon Dis. 2018; 13:1421-1431. doi: 10.2147/COPD.S157953.

19. Stratev V, Petkova D, Dimitrova V, Petev J. Comorbidities of COPD in Bulgarian Patients - Prevalence and Association with Severity and Inflammation. Folia Med (Plovdiv). 2018;60(1):102-109. doi:10.1515/folmed-2017-0078.

20. Ni Y, Shi G, Yu Y, Hao J, Chen T, Song H.Clinical characteristics of patients with chronic obstructive pulmonary disease with comorbid bronchiectasis: a systemic review and meta-analysis. Int J Chron Obstruct Pulmon Dis. 2015; 10:1465-1475. doi:10.2147/COPD.S83910.

21. Jairam PM, van der Graaf Y, Lammers JW, Mali WP, de Jong PA. Incidental findings on chest CT imaging are associated with increased COPD exacerbations and mortality. Thorax. 2015;70(8):725-731. doi:10.1136/thoraxjnl-2014-206160.

22. Smith IE, Jurriaans E, Diederich S, Ali N, Shneerson JM, Flower CD. Chronic sputum production: correlations between clinical features and findings on high resolution computed tomographic scanning of the chest. Thorax. 1996;51(9):914-918. PMID:8984702.

23. Vogelmeier CF, Criner GJ, Martinez FJ, Anzueto A, Barnes PJ, Bourbeau J, et al. Global Strategy for the Diagnosis, Management, and Prevention of Chronic Obstructive Lung Disease 2017 Report. GOLD Executive Summary. Am J Respir Crit Care Med. 2017;195(5):557-582. doi:10.1164/rccm.201701-0218PP.

24. Naidich DP, McCauley DI, Khouri NF, Stitik FP, Siegelman SS.Computed tomography of bronchiectasis. J Comput Assist Tomogr. 1982;6(3):437-444. PMID:7096687.

25. Lynch DA, Newell JD, Tschomper BA, Cink TM, Newman LS, Bethel R.Uncomplicated asthma in adults: comparison of CT appearance of the lungs in asthmatic and healthy subjects. Radiology. 1993;188(3):829-833. doi:10.1148/radiology.188.3.8351357.

26. Tan WC, Hague CJ, Leipsic J, Bourbeau J, Zheng L, Li PZ, et al. Findings on Thoracic Computed Tomography Scans and Respiratory Outcomes in Persons with and without Chronic Obstructive Pulmonary Disease: A Population-Based Cohort Study. PLoS One. 2016;11(11): e0166745. doi:10.1371/journal.pone.0166745.

27. Zalacain R, Sobradillo V, Amilibia J, Barrón J, Achótegui V, Pijoan Jl, et al. Predisposing factors to bacterial colonization in chronic obstructive pulmonary disease. Eur Respir J. 1999;13(2):343-348. PMID:10065679.

28. Jansen HM, Sachs AP, van Alphen L. Predisposing conditions to bacterial infections in chronic obstructive pulmonary disease. Am J Respir Crit Care Med. 1995;151(6):2073-2080. doi:10.1164/ajrccm.151.6.7767560. 
29. Soler-Cataluña JJ, Martínez-García MA, Román Sánchez P, Salcedo E, Navarro M, Ochando R. Severe acute exacerbations and mortality in patients with chronic obstructive pulmonary disease. Thorax. 2005 Nov;60(11):925-931. doi:10.1136/thx.2005.040527.

30. Hurst JR, Vestbo J, Anzueto A, Locantore N, Müllerova H, Tal-Singer R, et al. Susceptibility to exacerbation in chronic obstructive pulmonary disease. N Engl J Med. 2010 Sep 16;363(12):1128-1138. doi:10.1056/NEJMoa0909883.

31. O'Donnell AE. Bronchiectasis in patients with COPD: a distinct COPD phenotype? Chest. 2011;140(5):1107-1108. doi:10.1378/chest.11-1484.

32. Angrill J, Agustí C, De Celis R, Rañó A, Gonzalez J, Solé T, Xaubet A, Rodriguez-Roisin R, Torres A. Bacterial colonization in patients with bronchiectasis: microbiological pattern and risk factors. Thorax. 2002;57(1):15-19. PMID:11809984.

33. Rodrigo-Troyano A, Suarez-Cuartin G, Peiró M, Barril S, Castillo D, Sanchez-Reus F, et al. Pseudomonas aeruginosa resistance patterns and clinical outcomes in hospitalized exacerbations of COPD. Respirology. 2016;21(7):1235-1242. doi:10.1111/resp.12825.

34. Mekov E, Slavova Y, Tsakova A, Genova MP, Kostadinov DT, Minchev D, et al. One-year mortality after severe COPD exacerbation in Bulgaria. PeerJ. 2016 Dec 13;4:e2788. doi:10.7717/peerj.2788.

\section{Tables}

Table 1 Baseline and clinical characteristics of COPD subjects with and without bronchiectasis 


\begin{tabular}{|c|c|c|c|c|}
\hline Parameter & Whole Group & $\begin{array}{l}\text { COPD with } \\
\text { bronchiectasis }\end{array}$ & $\begin{array}{l}\text { COPD without } \\
\text { bronchiectasis }\end{array}$ & $\begin{array}{l}\mathrm{p}- \\
\text { value }\end{array}$ \\
\hline Subjects, n (\%) & $748(100)$ & $318(42.5)$ & $430(57.5)$ & - \\
\hline Male, n (\%) & $\begin{array}{l}550(73.5) \\
\square 73.6 \% \rrbracket\end{array}$ & $246(77.4)$ & $304(70.7)$ & 0.041 \\
\hline Age, y & $\begin{array}{l}73.06 \pm 9.34 \\
\square 9.36 \rrbracket\end{array}$ & $73.23 \pm 9.36$ & $72.93 \pm 9.33$ & 0.736 \\
\hline Body mass index, $\mathrm{kg} / \mathrm{m} 2$ & $23.27 \pm 4.55$ & $22.74 \pm 4.58$ & $23.68 \pm 4.49$ & 0.011 \\
\hline Smoking history, n (\%) & $587(78.5)$ & $249(78.3)$ & $338(78.6)$ & 0.921 \\
\hline Pack-years smoked & $41.31 \pm 29.21$ & $38.75 \pm 25.36$ & $43.20 \pm 31.66$ & 0.273 \\
\hline $\begin{array}{l}\text { Time since onset of } \\
\text { symptoms, y }\end{array}$ & $16.53 \pm 13.43$ & $17.43 \pm 13.48$ & $15.86 \pm 13.37$ & 0.051 \\
\hline Daily expectoration, n (\%) & $698(93.3)$ & $299(94.0)$ & $399(92.8)$ & 0.504 \\
\hline History of dyspnea, y & $12.09 \pm 12.09$ & $13.12 \pm 12.31$ & $11.32 \pm 11.88$ & 0.022 \\
\hline Ischemic heart disease, $\mathrm{n}(\%)$ & $172(23.0)$ & $65(20.4)$ & 107(24.9) & 0.153 \\
\hline Arrhythmias, n (\%) & $54(7.2)$ & $19(6)$ & $35(8.1)$ & 0.258 \\
\hline Heart failure, n (\%) & $80(10.7)$ & $27(8.5)$ & $53(12.3)$ & 0.093 \\
\hline Previous tuberculosis, n (\%) & $69(9.2)$ & $36(11.3)$ & $33(7.7)$ & 0.088 \\
\hline $\begin{array}{l}\text { Pulmonary heart disease, } n \\
(\%)\end{array}$ & 262(35.0) & 118(37.1) & 144(33.5) & 0.305 \\
\hline $\begin{array}{l}\text { Hospital admission in the } \\
\text { previous year, } \mathrm{n}(\%)\end{array}$ & $231(30.9)$ & $100(31.4)$ & $131(30.5)$ & 0.774 \\
\hline Length of hospitalization, $d$ & $10.41 \pm 4.69$ & $10.63 \pm 5.06$ & $10.25 \pm 4.39$ & 0.590 \\
\hline Albumin, $\mathrm{mg} / \mathrm{dL}$ & $32.99 \pm 4.40$ & $32.92 \pm 4.52$ & $33.04 \pm 4.31$ & 0.799 \\
\hline fibrinogen & $345.14 \pm 110.451$ & $357.69 \pm 108.68$ & $335.84 \pm 110.96$ & 0.005 \\
\hline
\end{tabular}


Patients with PPMs isolates, $\quad 83$ (11.1)

$38(11.9)$

$45(10.5)$

0.523

n (\%)

\section{Pseudomonas aeruginosa $\quad 36(4.8)$} isolates, $\mathrm{n}(\%)$

$21(6.6)$

$15(3.5)$

0.049

Notes: Data are presented as number (\%) or mean \pm SD unless specified.

Abbreviations: COPD, Chronic Obstructive Pulmonary Disease; PPMs, potential pathogenic microorganisms.

Table 2 Baseline pulmonary function of COPD subjects with and without bronchiectasis

\begin{tabular}{llllc} 
Parameter & $\begin{array}{l}\text { Whole } \\
\text { Group }\end{array}$ & $\begin{array}{l}\text { COPD with } \\
\text { bronchiectasis }\end{array}$ & $\begin{array}{l}\text { COPD without } \\
\text { bronchiectasis }\end{array}$ & $\begin{array}{l}\text { p- } \\
\text { value }\end{array}$ \\
\hline Subjects* & $306(100)$ & $123(40.2)$ & $183(59.8)$ & - \\
\hline $\begin{array}{l}\text { Postbronchodilator } \\
\text { FEV1(L) }\end{array}$ & $1.11 \pm 0.41$ & $1.06 \pm 0.38$ & $1.15 \pm 0.42$ & 0.058 \\
\hline Predicted \% & $47.28 \pm 17.94$ & $44.25 \pm 16.6$ & $49.32 \pm 18.55$ & 0.013 \\
\hline $\begin{array}{l}\text { Post-bronchodilator FVC } \\
\text { (ml) }\end{array}$ & $2.37 \pm 0.63$ & $2.37 \pm 0.63$ & $2.37 \pm 0.63$ & 0.75 \\
\hline Predicted \% & $77.36 \pm 19.36$ & $75.89 \pm 20.86$ & $78.34 \pm 18.29$ & 0.135 \\
\hline FEV1/FVC \% predicted & $46.52 \pm 9.72$ & $44.52 \pm 9.04$ & $47.87 \pm 9.95$ & 0.003
\end{tabular}

Notes: Data are presented as number (\%) or mean \pm SD unless specified.

Abbreviations: FEV1, forced expiratory volume in 1 second; FVC, forced vital capacity.

*The total number of lung functions available for data analysis was 306 . The total number of comorbid bronchiectasis patients with lung functions available was 123 , the total number of non-bronchiectasis patients with lung function available was 183.

Table 3 Association between the presence of bronchiectasis and death of COPD 
Unadjusted

\begin{tabular}{|c|c|c|c|c|}
\hline Variables & $\mathrm{HR} \otimes 95 \% \mathrm{Cl} \mathbb{}$ & $\begin{array}{l}\mathrm{p}- \\
\text { value }\end{array}$ & $\mathrm{HR}(95 \% \mathrm{Cl})$ & $\begin{array}{l}\mathrm{p}- \\
\text { value }\end{array}$ \\
\hline Age & $\begin{array}{l}1.052(1.034- \\
1.069)\end{array}$ & $<0.001$ & $\begin{array}{l}1.047(1.030- \\
1.065 \rrbracket\end{array}$ & $<0.001$ \\
\hline Length of hospitalization & $\begin{array}{l}1.035(1.023- \\
1.047)\end{array}$ & $<0.001$ & $\begin{array}{l}1.026(1.008- \\
1.043)\end{array}$ & 0.003 \\
\hline Albumin & $\begin{array}{l}0.938(0.91- \\
0.968)\end{array}$ & $<0.001$ & $\begin{array}{l}0.949(0.919- \\
0.980)\end{array}$ & 0.001 \\
\hline $\begin{array}{l}\text { Hospital admission in the previous } \\
\text { year }\end{array}$ & $\begin{array}{l}1.696(1.288- \\
2.234)\end{array}$ & $<0.001$ & $\begin{array}{l}1.487(1.119- \\
1.977)\end{array}$ & 0.006 \\
\hline Bronchiectasis & $\begin{array}{l}1.580(1.204- \\
2.072)\end{array}$ & 0.001 & $\begin{array}{l}1.504(1.144- \\
1.978)\end{array}$ & 0.003 \\
\hline Pulmonary heart disease & $\begin{array}{l}1.764(1.345- \\
2.312)\end{array}$ & $<0.001$ & $\begin{array}{l}1.472(1.113- \\
1.946)\end{array}$ & 0.007 \\
\hline
\end{tabular}

Abbreviations: $\mathrm{HR}$, hazard ratio; $\mathrm{Cl}$, confidence interval.

Table 4 Association between bronchiectasis total score and death of COPD

\begin{tabular}{|c|c|c|c|c|}
\hline & Unadjusted & & Fully Adjusted & \\
\hline Variables & $\mathrm{HR} \rrbracket 95 \% \mathrm{Cl} \rrbracket$ & $\begin{array}{l}p- \\
\text { value }\end{array}$ & $\mathrm{HR}(95 \% \mathrm{Cl})$ & $\begin{array}{l}\mathrm{p}- \\
\text { value }\end{array}$ \\
\hline Age & $\begin{array}{l}1.052(1.034- \\
1.069)\end{array}$ & $<0.001$ & $\begin{array}{l}1.048(1.030- \\
1.065 \rrbracket\end{array}$ & $<0.001$ \\
\hline Length of hospitalization & $\begin{array}{l}1.035(1.023- \\
1.047)\end{array}$ & $<0.001$ & $\begin{array}{l}1.027(1.009- \\
1.045)\end{array}$ & 0.002 \\
\hline Albumin & $\begin{array}{l}0.938(0.91- \\
0.968)\end{array}$ & $<0.001$ & $\begin{array}{l}0.951(0.921- \\
0.982)\end{array}$ & 0.002 \\
\hline $\begin{array}{l}\text { Hospital admission in the previous } \\
\text { year }\end{array}$ & $\begin{array}{l}1.696(1.288- \\
2.234)\end{array}$ & $<0.001$ & $\begin{array}{l}1.501(1.130- \\
1.992)\end{array}$ & 0.005 \\
\hline Bronchiectasis total score & $\begin{array}{l}1.062(1.011- \\
1.115)\end{array}$ & 0.016 & $\begin{array}{l}1.058(1.007- \\
1.112)\end{array}$ & 0.026 \\
\hline Pulmonary heart disease & $\begin{array}{l}1.764(1.345- \\
2.312)\end{array}$ & $<0.001$ & $\begin{array}{l}1.492(1.129- \\
1.972)\end{array}$ & 0.005 \\
\hline
\end{tabular}

Abbreviations: $\mathrm{HR}$, hazard ratio; $\mathrm{Cl}$, confidence interval. 
Table 5 Clinical Characteristic of COPD subjects with bronchiectasis according to the types of bronchiectasis 


\begin{tabular}{|c|c|c|c|c|}
\hline Parameter & Whole group & $\begin{array}{l}\text { Cystic/Varicose } \\
\text { bronchiectasis }\end{array}$ & $\begin{array}{l}\text { Cylindrical } \\
\text { bronchiectasis }\end{array}$ & $\begin{array}{l}p- \\
\text { value }\end{array}$ \\
\hline Subjects & $318(100)$ & $59(18.6)$ & $259(81.4)$ & -- \\
\hline Age, y & $73.23 \pm 9.36$ & $72.9 \pm 9.44$ & $73.31 \pm 9.36$ & 0.682 \\
\hline Male, n(\%) & $246(77.4)$ & 47(79.7) & 199(76.8) & 0.640 \\
\hline $\begin{array}{l}\text { Body mass index, } \\
\mathrm{kg} / \mathrm{m} 2\end{array}$ & $22.74 \pm 4.58$ & $23.06 \pm 4.11$ & $22.68 \pm 4.67$ & 0.606 \\
\hline Smoking history, n(\%) & $249(78.3)$ & $43(72.9)$ & $206(79.5)$ & 0.263 \\
\hline Pack-years smoked & $38.77 \pm 25.41$ & $37.95 \pm 27.07$ & $38.94 \pm 25.11$ & 0.615 \\
\hline $\begin{array}{l}\text { Time since onset of } \\
\text { symptoms, y }\end{array}$ & $17.43 \pm 13.48$ & $19.42 \pm 14.41$ & $16.97 \pm 13.25$ & 0.282 \\
\hline History of dyspnea, y & $13.12 \pm 12.31$ & $14.40 \pm 13.62$ & $12.84 \pm 12.00$ & 0.529 \\
\hline $\begin{array}{l}\text { Previous tuberculosis, } \mathrm{n} \\
(\%)\end{array}$ & $36(11.3)$ & $5(8.5)$ & $31(12.0)$ & 0.445 \\
\hline $\begin{array}{l}\text { Ischemic heart disease, } \\
\text { n (\%) }\end{array}$ & $65(20.4)$ & $10(16.9)$ & $55(21.2)$ & 0.461 \\
\hline Arrhythmias, n (\%) & $19(6.0)$ & $3(5.1)$ & $16(6.2)$ & 0.749 \\
\hline Heart failure, n (\%) & $27(8.5)$ & $3(5.1)$ & $24(9.3)$ & 0.298 \\
\hline $\begin{array}{l}\text { Pulmonary heart } \\
\text { disease, } \mathrm{n}(\%)\end{array}$ & 118(37.1) & $22(37.3)$ & $96(37.1)$ & 0.975 \\
\hline $\begin{array}{l}\text { Hospital admission in } \\
\text { the previous year, } \mathrm{n}(\%)\end{array}$ & $100(31.4)$ & $23(39)$ & 77(29.7) & 0.167 \\
\hline $\begin{array}{l}\text { Length of } \\
\text { hospitalization, d }\end{array}$ & $10.63 \pm 5.06$ & $11.81 \pm 6.93$ & $10.37 \pm 4.51$ & 0.195 \\
\hline Albumin, mg/dL & $32.92 \pm 4.52$ & $31.92 \pm 5.37$ & $33.15 \pm 4.28$ & 0.115 \\
\hline Fibrinogen & $\begin{array}{l}357.69 \pm 108.68 \\
\text { YIHIHI11108.68110.65 }\end{array}$ & $337.61 \pm 106.64$ & $362.16 \pm 108.83$ & 0.072 \\
\hline Hemoglobin $\mathrm{g} / \mathrm{L}$ & $134.10 \pm 21.86$ & $132.41 \pm 26.15$ & $134.48 \pm 20.79$ & 0.650 \\
\hline $\begin{array}{l}\text { Patients with PPMs } \\
\text { isolates, } \mathrm{n}(\%)\end{array}$ & $38(11.9)$ & $8(13.6)$ & $30(11.6)$ & 0.673 \\
\hline $\begin{array}{l}\text { Pseudomonas } \\
\text { aeruginosa isolates, } \mathrm{n} \\
(\%)\end{array}$ & $21(6.6)$ & $8(13.6)$ & $13(5.0)$ & 0.017 \\
\hline $\begin{array}{l}\text { All-cause mortality*, n } \\
(\%)\end{array}$ & $112(41.2)$ & $28(53.8)$ & $84(38.2)$ & 0.039 \\
\hline
\end{tabular}


Notes: Data are presented as number (\%) or mean \pm SD unless specified.

*A total of 272 patients with chronic obstructive pulmonary disease associated with bronchiectasis were followed up, 112 of whom died during the study.

Abbreviations: PPMs, potential pathogenic microorganisms.

Table 6 Association between the types of bronchiectasis and death of COPD patients with bronchiectasis

\begin{tabular}{|c|c|c|c|c|}
\hline & Unadjusted & & Fully Adjusted & \\
\hline Variables & $\mathrm{HR}(95 \% \mathrm{Cl} \nabla$ & $\begin{array}{l}\mathrm{p}- \\
\text { value }\end{array}$ & $\mathrm{HR} \otimes 95 \% \mathrm{Cl} \mathbb{\nabla}$ & $\begin{array}{l}\mathrm{p}- \\
\text { value }\end{array}$ \\
\hline Age & $\begin{array}{l}1.049(1.027- \\
1.072)\end{array}$ & 0.001 & $\begin{array}{l}1.046(1.023- \\
1.069)\end{array}$ & $<0.001$ \\
\hline Length of hospitalization & $\begin{array}{l}1.034(1.021- \\
1.048)\end{array}$ & 0.001 & $\begin{array}{l}1.028(1.013- \\
1.044)\end{array}$ & $<0.001$ \\
\hline Bronchiectasis type & $\begin{array}{l}1.680(1.094- \\
2.581)\end{array}$ & 0.018 & $\begin{array}{l}1.683(1.084- \\
2.612)\end{array}$ & 0.020 \\
\hline $\begin{array}{l}\text { Previous tuberculosis } \\
\text { tuberculosis }\end{array}$ & $\begin{array}{l}1.623 \otimes 0.968- \\
2.720 \rrbracket\end{array}$ & 0.066 & $\begin{array}{l}1.691 \rrbracket 1.006- \\
2.844 \rrbracket\end{array}$ & 0.048 \\
\hline Pulmonary heart disease & $\begin{array}{l}1.768 \rrbracket 1.220- \\
2.562 \rrbracket\end{array}$ & 0.003 & $\begin{array}{l}1.632 \rrbracket 1.118- \\
2.384 \rrbracket\end{array}$ & 0.011 \\
\hline
\end{tabular}

Abbreviations: $\mathrm{HR}$, hazard ratio; $\mathrm{Cl}$, confidence interval.

\section{Figures}




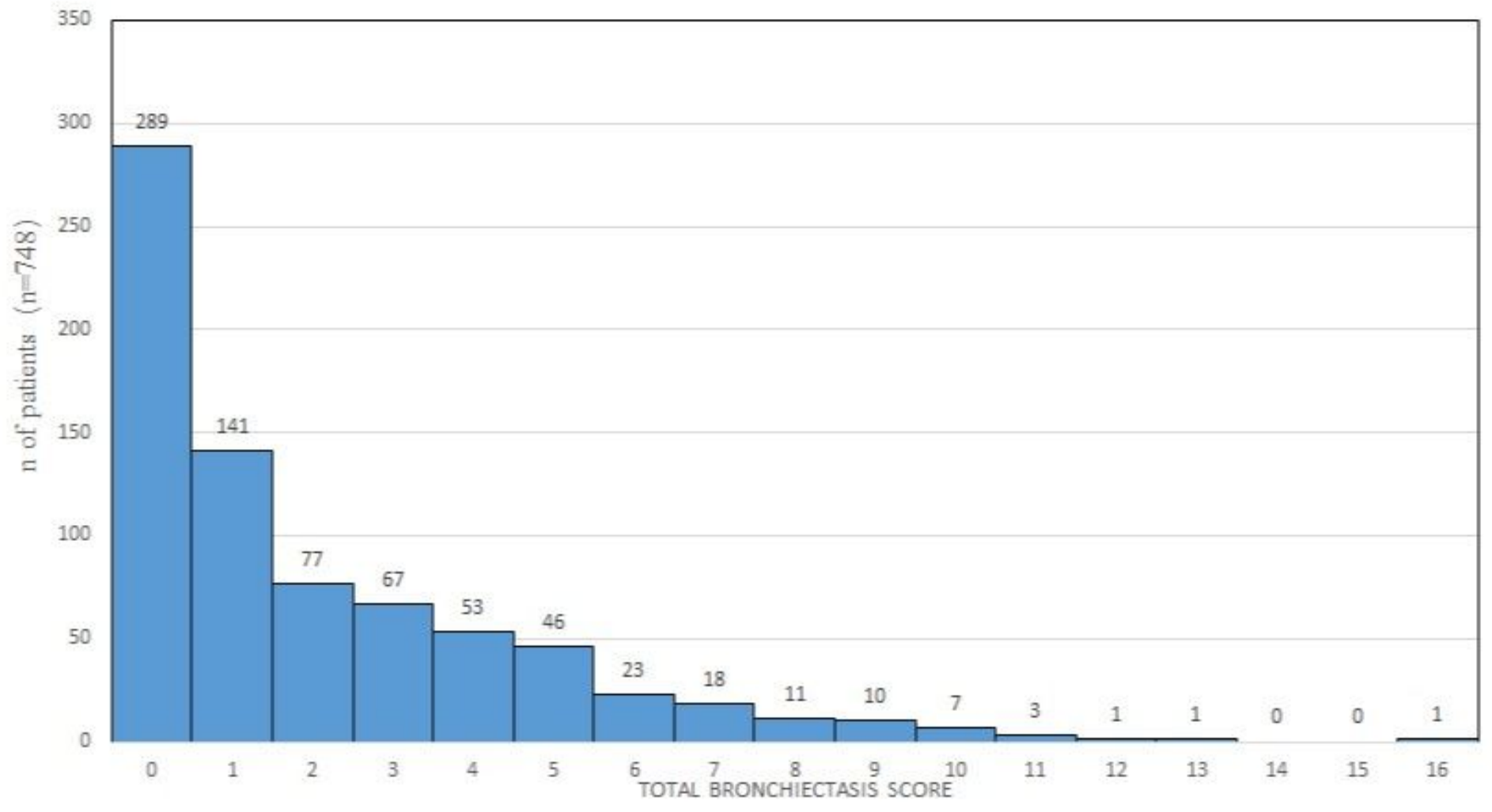

Figure 1

Total bronchiectasis score

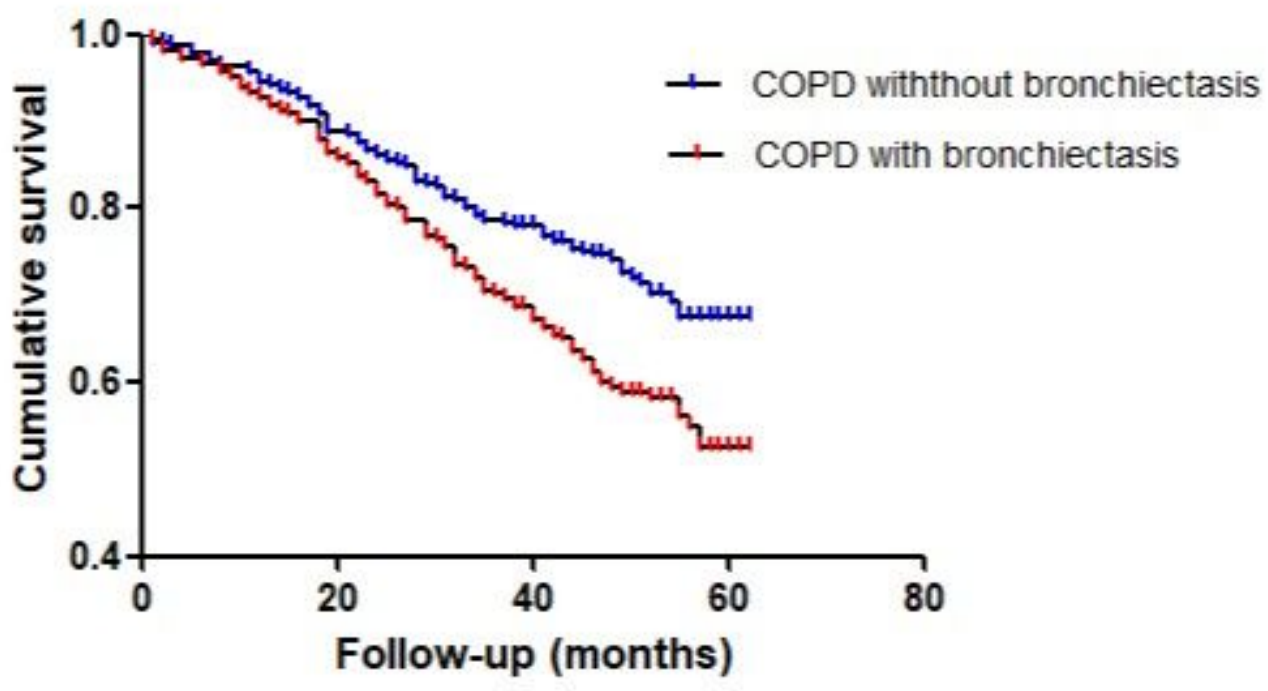

Figure 2

Kaplan-Maier survival curves between COPD patients with and without bronchiectasis groups (log-rank test 11.201, $p=0.001$. 


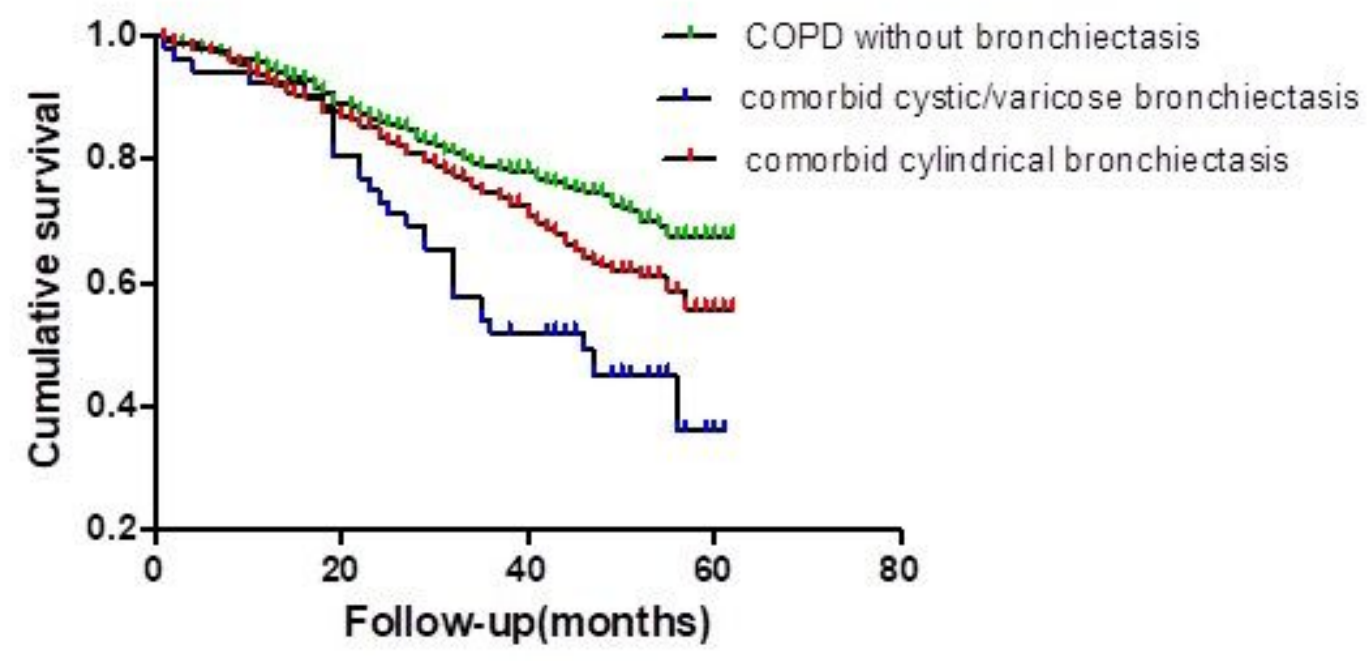

Figure 3

Kaplan-Maier survival curves among non-bronchiectasis and cystic /varicose bronchiectasis and cylindrical bronchiectasis groups (log-rank test18.201, p<0.001).

\section{Supplementary Files}

This is a list of supplementary files associated with this preprint. Click to download.

- supplement1.docx 